\title{
Applicability and effect of a vacuum-assisted wound therapy after median laparotomy in horses
}

\author{
Moritz Gaus', Karl Rohn² and Anna K. Roetting' \\ 1 Equine Clinic, University of Veterinary Medicine Hannover, Germany \\ 2 Institute for Biometry, Epidemiology and Information Processing, University of Veterinary Medicine Hannover, Germany
}

\begin{abstract}
Summary: In a randomized, prospective, clinical trial the applicability of a vacuum therapy system was evaluated at the ventral abdomen in 50 horses with laparotomy due to acute abdominal pain. The effects on the incidence of wound healing complications after ventral median laparotomy in horses with acute abdominal pain is described. The horses were allocated to the treatment or control group after laparotomy and equipped with a wound dressing and a vacuum $(125 \mathrm{mmHg})$ or with the wound dressing alone. Relevant parameters were collected preoperatively, intraoperatively, six consecutive days postoperatively, and three and eight weeks after surgery. Pre-, intra- and postoperative parameters were not significantly different between the groups. Nine horses (36\%) in the treatment group and four horses $(16 \%)$ in the control group developed a wound healing complication. This difference was not statistically significant and neither were the differences in oedema formation and the occurrence of dehiscence. No significant differences concerning exudation, oedema or dehiscence were found between the groups three and eight weeks after surgery. Overall, the vacuum system used in this study is an easy to apply system for general use at the ventral abdomen of the horse, with good toleration by the patients. The results indicate that the use of vacuum therapy for primary closed wounds after median laparotomy has no beneficial effect on wound healing.
\end{abstract}

Keywords: horse, ventral median laparotomy, colic, wound healing complication, negative pressure wound therapy, vacuum-assisted closure

Citation: Gaus M., Rohn K., Roetting A. K. (2017) Applicability and effect of a vacuum-assisted wound therapy after median laparotomy in horses. Pferdeheilkunde 33, 563-572; DOI 10.21836/PEM20170604

Correspondence: Dr. Moritz Gaus, Veterinary University Hannover Foundation, Clinic for horses, Buenteweg 9, 30559 Hannover, Germany; moritz.gaus@tiho-hannover.de

\section{Introduction}

Negative pressure wound therapy (NPWT), also called negative pressure therapy (NPT) or vacuum-assisted closure (VAC ${ }^{\circledR}, \mathrm{KCl}$ Medizinprodukte $\mathrm{GmbH}$, Wiesbaden, Germany) was introduced in human medicine in 1997 and has become an integral component in managing various types of open and chronic wounds often associated with loss of tissue (Argenta and Morykwas 1997, Blackham et al. 2013, Morywas et al. 1997).

Two primary mechanisms of action have been suggested for the effect of NPWT on this type of wounds. Firstly, the vacuum applied evacuates the potential death space of the wound and facilitates exudate removal (Banwell 1999). Exudate egress results in an interstitial fluid gradient shift (Morykwas et al. 1997) with various positive effects: reduction of oedema via the removal of proinflammatory mediators, secondary increase of dermal perfusion and removal of wound debris (Banwell and Musgrave 2004). The second primary effect of NPWT is mechanical stress resulting in microdeformation of the wound surface, contraction of the surrounding skin and the release of growth factors, thereby increasing cell proliferation (Saxena et al. 2004).

Some authors recently reported the successful usage of NPWT on closed surgical incisions in high-risk orthopaedic surgeries and post-sternotomy patients (Atkins et al. 2009, Gomoll et al. 2006, Reddix at al. 2009, Stannard et al. 2006, Stannard et al. 2009). The incidence of wound complications after laparotomy in high-risk oncology patients was significantly lower for patients treated with NPWT (6.7 vs.
19.5\%; Blackham et al. 2013). The overall risk of wound complications after abdominal wall reconstruction was $22 \%$ in the vacuum group compared to $63.6 \%$ in the control group, and the rates of skin dehiscence were 9 and $39 \%$, respectively (Condé-Green et al. 2013). A potential reason for the effectiveness of NPWT on closed primary incisions beyond the above mentioned mechanisms could be bolstering of the incision line and thereby reduction of shearing forces. An in vitro study using finite element analysis and a benchtop model showed that the lateral tension at the suture line was decreased by $50 \%$ and the lines of tension were normalized to preincisional levels after application of topical negative pressure. The authors concluded that application of a vacuum system to primary closed incisions could reduce distracting and prevent shearing forces, thereby acting as a splint to the incisional margins (Wilkes et al. 2012).

Wound healing complications are a common problem after ventral median laparotomy in horses and the incidence described varies between 7.4 and $37 \%$ in different studies (Freeman et al. 2000, Honnas and Cohen 1997, Kobluk et al. 1989, Mair and Smith 2005, Phillips and Walmsley 1993, Proudman et al. 2002). The use of vacuum therapy in horses has been reported for treatment of a chronic neck wound and improvement of skin graft acceptance (Gemeinhardt and Molnar 2005, Jordana et al. 201 1, Rijkenhuizen et al. 2005). A more recent report described the successful use of vacuum therapy for the treatment of a septic arthritis of the carpus (Rettig and Lischer 2015). To the best of our knowledge, the use of NPWT at the ventral abdomen or for the treatment of primary closed wounds has not been described in horses. 
The object of this study was to evaluate the applicability of a NPWT system at the ventral abdomen of the horse and to describe its effect on the likelihood of wound healing complications after ventral median laparotomy in horses with acute abdominal pain. It was hypothesized that the use of NPWT would decrease the frequency of wound healing complications after exploratory laparotomy.

\section{Material and Methods}

Fifty horses were included in the study. Inclusion criteria were that horses underwent exploratory laparotomy due to acute abdominal pain through ventral midline coeliotomy at the Equine Clinic of the University of Veterinary Medicine in Hannover. Horses had to be older than one year of age due to the potential difficulties of attaching the vacuum system to very young horses. Recovery from surgery and survival for a six-day postoperative period were also mandatory.

All horses were prepared for surgery in the same manner. The hair was clipped immediately preoperatively and the ventral abdomen was aseptically prepared with chlorhexidine (Hibiscrub, Mölnlycke Health Care GmbH, Erkrath-Unterfeldhaus, Germany) and sterile saline solution. Wound closure was performed in two layers. The abdominal wall was sutured in a simple continuous pattern with a size 6 USP Polyglactin 910 (Vicryl, Johnson \& Johnson Medical GmbH Ethicon, Norderstedt, Germany) and the skin was closed in a simple continuous suture pattern with a size 2/0 USP Polyglactin 910 (Vicryl, Johnson \& Johnson Medical GmbH Ethicon, Norderstedt, Germany). For recovery, the incisional wound was covered with sterile gauze and an adhesive drape, which was a transparent and breathable polyurethane film (Opsite* Incise ${ }^{\circledR}$, Smith and Nephew GmbH, Hamburg, Germany). This wound coverage was removed after recovery when the horses were standing safely. The skin around the incision line was cleaned with alcohol (Softasept ${ }^{\circledR}$ N, B. Braun Melsungen AG, Melsungen, Germany).

After recovery, the horses were divided into four groups as follows: ponies, horses 1-10 years, horses $11-20$ years and horses $>20$ years. The horses within each group were than allocated to either the treatment or the control group in an alternating manner. This procedure was chosen to minimize any potential effect of time of year on treatment or pony breed.

In the treatment group, the wounds were covered with a silver-impregnated wound dressing, including a sponge for vacuum application (Prevena ${ }^{\mathrm{TM}}$ Customizable $^{\mathrm{TM}}$ Incision Management System, KCl Medizinprodukte $\mathrm{GmbH}$, Wiesbaden, Germany) (Fig. 1). This sponge was then covered with an air- and water-impermeable adhesive drape and a suction tube was attached onto the sponge over a small hole cut into the drape at this position. Adhesive spray (Adhäsiv-Sprühkleber WDT $^{\circledR}$, Wirtschaftsgenossenschaft deutscher Tierärzte e.G., Garbsen, Germany) was used around the incision to improve the fixation of the drape. The tube was then connected to a vacuum pump (Acti-V.A.C ${ }^{\circledR}, \mathrm{KCl}$ Medizinprodukte $\mathrm{GmbH}$, Wiesbaden, Germany) (Fig.2) that maintained a continuous negative pressure of $125 \mathrm{mmHg}$. The vacuum system consisted of a pump with an integrated battery and touch screen for control. A fluid collection tank was attached to the pump and this setting was attached to the neck of the horse in a product-specific carrying bag. During vacuum application the horses were observed for adverse reactions, e. g. kikking, putting on ears, waving the tail or biting. In the control group, the wound was covered with the identical silverimpregnated wound dressing with the sponge removed

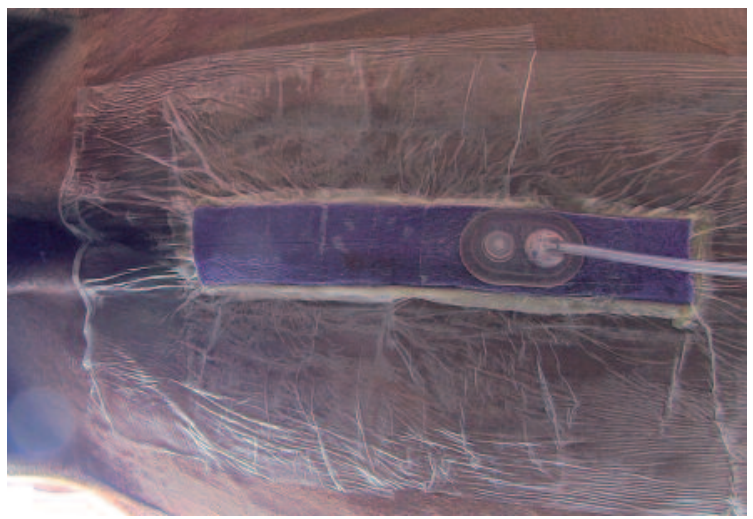

Abb. 1 Prevena $^{\text {TM }}$ Incision Management System at the ventral abdomen of the horse after application of vacuum. I Prevena ${ }^{\text {TM }}$ Incision Management System am ventralen Abdomen eines Pferd nach Anlegen des Vakuums

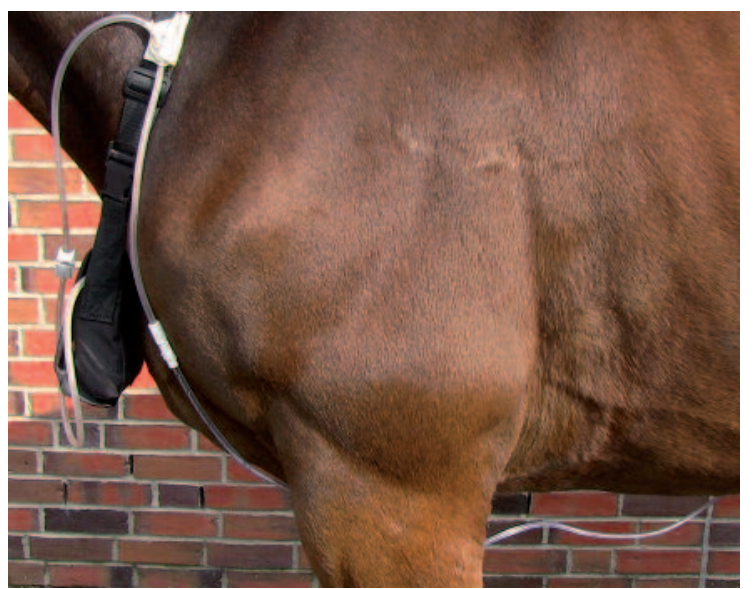

Fig. 1 Portable, battery-based vacuum pump attached with a bag around the horse's neck | Tragbare, batteriebetriebene Vakuumpumpe, fixiert am Hals des Pferdes

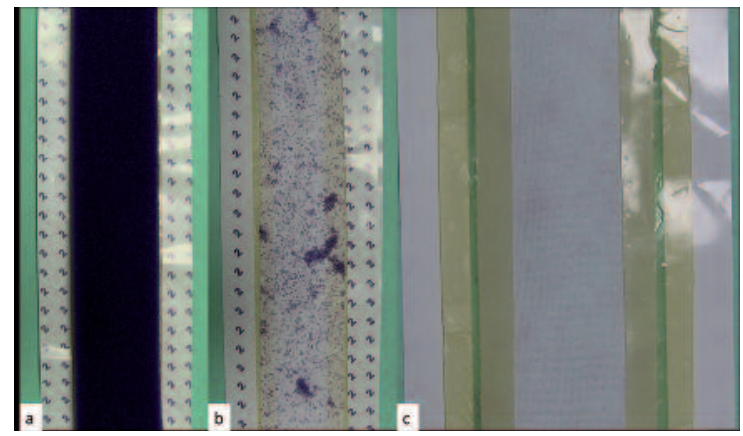

Fig. 3 Prevena $^{\mathrm{TM}}$ Incision Management System: a) polyurethane foam at the far side of the wound, b) foam removed for better fixation in the control group and c) silver-impregnated webbing facing the wound.

Prevena ${ }^{T M}$ Incision Management System: a) Polyurethan Schwamm der Wundauflage b) Wundauflage mit entferntem Schwamm zur verbesserten Fixation in der Kontrollgruppe c) Silber-imprägniertes Gewebe, Wundkontaktfläche 
(Fig. 3), and covered with an adhesive drape (Opsite* Incise ${ }^{\circledR}$, Smith and Nephew GmbH, Hamburg, Germany). Sedation and/or a nose twitch for application or removal of wound dressings were used per judgement of the attending veterinarian. Two people were necessary for wound dressing application in both groups.

Data were recorded as follows at different time points: preoperatively, intraoperatively, for six consecutive days postoperatively, and three and eight weeks after surgery via telephone interview. Preoperative recorded parameters were age, weight, heart rate, duration of colic, degree of visceral pain in a range from 0 to $3(0=$ no pain, $1=$ anorexia, flehming, 2 = pawing, lying down, 3 = rolling, sweating), and various haematological parameters (packed cell volume, white blood cell count and blood lactate). Intraoperative variables included duration of general anaesthesia, incisional length, primary lesion and performance of an enterotomy or an intestinal resection. Four procedure groups were defined, consisting of large intestinal procedures with or without enterotomy (LIE, LI) and small intestinal procedures with or without resection (SIR, SI). For the first 6 consecutive postoperative days, heart rate, temperature and white blood cell count (if available) were recorded. The layer thickness of the collateral oedema formation around the incision was estimated at the lateral edge of the oedema, scaled from 0 to $3(0=$ no oedema, $1=1-2 \mathrm{~cm}$ thickness, $2=2-5 \mathrm{~cm}$ thickness, $3=>5 \mathrm{~cm}$ thikkness), and daily recorded for the first 6 consecutive postoperative days.

The wound dressing in both groups was left in place for the six-day period. If the incisional coverage of the control group became insufficient or a leakage of a vacuum system of the treatment group occurred, the wound dressing was renewed. The complete wound dressing was removed at day six and the incision was inspected. The amount of exudation was estimated and graded from 0 to $3(0=$ no exudation, $1=<5 \mathrm{ml}$, $2=6-15 \mathrm{ml}, 3=>15 \mathrm{ml}$ ) and skin dehiscence was graded from 0 to 3 ( $0=$ no dehiscence, $1=$ partial length of the suture and $>1 \mathrm{~cm}$ width, $2=$ partial length and $>1 \mathrm{~cm}$ width or full length and $<1 \mathrm{~cm}$ width, and $3=$ full length and $>1 \mathrm{~cm}$ width). The incision continued to be evaluated every day for horses that were hospitalized longer than six days. Amount and character of wound exudate was recorded at day 6 .

The owners were contacted via telephone three and eight weeks after surgery and the occurrence of incisional drainage, development of oedema and presence of skin dehiscence were recorded.

\section{Statistical analysis}

Quantitative data were checked for normal distribution using Shapiro Wilk test and visual assessment of $Q Q$ plots of model residuals. Due to the rejection of the normal distribution assumption the analysis of quantitative data was carried out with nonparametric tests. Wilcoxon-2-sample test was used for comparison of two independent samples. The development within the groups over the six day time period was calculated with Permutation test for random complete block design (repeated measurements, according to an exact Friedman test) with post-hoc sidak-test for multiple pairwise com- parisons, concerning the comparison wise and the experiment wise error-rate. Because of increasing of beta-error and loss of significant information, only results concerning comparison wise error-rate were depicted. Categorical data was analyzed by test Fischer exact test. Probability values $<0.05$ were considered to be statistically significant. Statistical analysis was performed using computerized statistical software SAS v9.3 (SAS Institute Cary, NC, USA)

\section{Results}

Of the 50 horses, 11 were allocated to group 1 (ponies), 22 to group 2 ( $1-10$ years), 14 to group 3 (1 1-20 years) and 3 horses were older than 20 (group 4). One horse for the treatment group was euthanized at day five and was excluded from the statistical analysis. One horse of the treatment group (day 9) and one horse of the control group (day 7) were euthanized after day six and, therefore, the follow-up data was incomplete.

Wound coverage for recovery did not slip and removal was tolerated well without any adverse reactions in all 50 horses. Attachment of the vacuum pump to the neck was well tolerated by all 25 animals of the treatment group. The initial application of the NPWT wound dressing to the ventral abdomen of the standing horse was easy to perform and was tolerated well. The application of $125 \mathrm{mmHg}$ Vacuum did not cause noticeable adverse reactions in any of the horses. Vacuum could not be established at initial application of the system and the wound dressing had to be replaced in 2 of the 25 horses in the treatment group. During the six-day postoperative period of the study a total of three dressings had to be replaced in the treatment group due to leakage and loss of vacuum. Also in these three patients no adverse reaction was observed. In all other horses the vacuum could be kept stable and functioned reliably throughout the six-day treatment period except for the short-period of battery (approximately twice a day) or fluid-collection tank exchange. The wound dressing had to be replaced in seven horses of the control group because of a deficit of adequate attachment. This was also possible without sedation. For final removal of the wound dressing in both groups nose twitch (five horses) and/or sedation (two horses) were necessary for the safe removal in some patients.

Pre- and intraoperative parameters recorded were not significantly different between the treatment and control groups and no differences were noted among each of the four groups within the treatment and the control group (Tab. 1). In addition, the values measured for heart rate, temperature, white blood cell count and oedema formation in the six postoperative days were not significantly different between the groups at any time point. There was a significant drop in the heart rate after day 1 in both treatment and control groups. The temperature showed no significant changes within the groups throughout the study. The oedema increased significantly between day 2 and 4 in all animals.

Nine horses in the treatment group (36\%) and four horses in the control group (16\%) developed incisional drainage. The latter occurred on day $6.5(\mathrm{SD}=1.13)$ and on day 7.5 $(S D=1.73)$, respectively. The median score of the drainage 
was $1.7(1: n=4,2: n=3,3: n=2)$ in the treatment group and $1(1: n=4)$ in the control group (Tab. 2).

The type of surgical procedure was relatively evenly distributed within the groups and had no significant influence on the occurrence of wound healing complications (Tab. 3).

In twenty-one horses of the treatment group fluid was accumulated in the collection tank. In 18 horses the volume of fluid was between 25 and $50 \mathrm{ml}$ and of water-like character. In 3 horses it was between 100 and $250 \mathrm{ml}$ and of serosanguinous character. Those 3 horses had a clinical apparent wound healing complication after removal of the wound dressing. In the horses of the control group no fluid accumulation was seen beneath the drape.

No significance was found between the groups regarding oedema formation, exudation and dehiscence formation at the telephone interviews three weeks after surgery. Owners reported that $56 \%(n=14)$ of the horses of the treatment group and $52 \%(n=13)$ of the horses of the control group had mild oedema formation. Five horses in the treatment group had ongoing exudation, whereas three horses of the control group showed persisting exudation. Skin dehiscence was still present in one of the two horses of the treatment group and was not present in any horse of the control group (Tab. 2).

Remaining oedema was reported in three horses of the treatment group and two horses of the control group after eight weeks. Exudation persisted in two horses of the treatment group and one of these showed a small skin dehiscence that was not present at three weeks or before. In this horse, skin closure was achieved within six days after wound debridement and removal of necrotic tissue with suture residuals. No significant differences between treatment and control group were detected at three and eight weeks after surgery for these three parameters.

Table 1 Pre- and intraoperative data (mean + standard deviation $( \pm)$ ), HR = heart rate, PCV $=$ packed cell volume, WBC $=$ white blood cell count | Prä- und intraoperative Daten (Mittelwert+ Standartabweichung( \pm )), HR=Herzferquenz, PCV = Hämatokrit, WBC $=$ Leukozytengehalt im Blut

\begin{tabular}{|c|c|c|c|c|}
\hline \multirow[b]{2}{*}{ preOP } & \multicolumn{2}{|c|}{ Treatment } & \multicolumn{2}{|c|}{ Control } \\
\hline & Mean & SD & Mean & SD \\
\hline Age (y) & 12.7 & \pm 6.3 & 11.5 & \pm 8.6 \\
\hline Weight $(\mathrm{kg})$ & 498.9 & \pm 124.2 & 487.8 & \pm 161.3 \\
\hline Duration of colic (h) & 10.5 & \pm 9.1 & 15.0 & \pm 13.4 \\
\hline Painscore $(0-3)$ & 1.8 & \pm 0.8 & 1.7 & \pm 0.9 \\
\hline $\mathrm{HR}$ (bpm) & 63.1 & \pm 13.2 & 63.7 & \pm 19.8 \\
\hline PCV (\%) & 40.5 & \pm 4.6 & 41.3 & \pm 7.9 \\
\hline $\operatorname{WBC}\left(10^{3} / \mu \mathrm{l}\right)$ & 9.9 & \pm 4.4 & 9.7 & \pm 3.7 \\
\hline Lactate $(\mathrm{mmol} / \mathrm{l})$ & 2.1 & \pm 1.3 & 2.73 & \pm 2.3 \\
\hline \multicolumn{5}{|l|}{ intraOP } \\
\hline Length of incision $(\mathrm{cm})$ & 23.4 & \pm 3.6 & 23.6 & \pm 3.9 \\
\hline Duration (min) & 131.2 & \pm 35.0 & 147.2 & \pm 50.5 \\
\hline Oxygenation $\left(\mathrm{PO}_{2} \mathrm{mmHg}\right)$ & 126.2 & \pm 95.8 & 152.1 & \pm 130.9 \\
\hline
\end{tabular}

Table 2 Oedema score: $(0=$ no oedema, $1=1-2 \mathrm{~cm}$ thickness, $2=2-5 \mathrm{~cm}$ thickness, $3=>5 \mathrm{~cm}$ thickness $)$, exudation score $(0=$ no exudation, $1=<5 \mathrm{ml}, 2=6-15 \mathrm{ml}, 3=>15 \mathrm{ml})$, skin dehiscence score $(0=$ no dehiscence, $1=$ partial length of the suture and $>1 \mathrm{~cm}$ width, $2=$ partial length and $>1 \mathrm{~cm}$ width or full length and $<1 \mathrm{~cm}$ width, $3=$ full length and $>1 \mathrm{~cm}$ width.

Ödemscore: $10=$ Kein Ödem, $1=1-2 \mathrm{~cm}$ Dicke, 2=2-5cm Dicke, 3=>5cm Dicke), Exsudationsscore $(0=$ Keine Exsudation, $1=<5 \mathrm{ml}, 2=6-15 \mathrm{ml}$, $3=>15 \mathrm{ml})$, Dehiszenzscore $(0=$ Keine Dehiszenz, $1=$ Teillänge der Naht und $<1 \mathrm{~cm}$ Breite, $2=$ Teillänge und $>1 \mathrm{~cm}$ Breite oder ganze Länge der Naht und $<1 \mathrm{~cm}$ Breite, 3=Ganze Länge der Naht $>1 \mathrm{~cm}$ Breite

\begin{tabular}{|c|c|c|c|c|c|c|}
\hline & \multicolumn{2}{|c|}{ Oedema } & \multicolumn{2}{|c|}{ Exudation } & \multicolumn{2}{|c|}{ Dehiscense } \\
\hline & Treatment & Control & Treatment & Control & Treatment & Control \\
\hline Number (horses) & 22 & 24 & 9 & 4 & 2 & 1 \\
\hline Day of max. mean score/ occurrence & 6 & 6 & 6.5 & 7.5 & 6.5 & 11 \\
\hline Max. mean score & 1.54 & 1.5 & 1.78 & 1 & 1.5 & 2 \\
\hline \multicolumn{7}{|l|}{3 Weeks } \\
\hline n (horses) & 16 & 11 & 5 & 3 & 1 & 0 \\
\hline mean score & 1 & 1.09 & 1.2 & 1 & 2 & 0 \\
\hline \multicolumn{7}{|l|}{8 Weeks } \\
\hline $\mathrm{n}$ (horses) & 3 & 2 & 2 & 0 & 1 & 0 \\
\hline mean score & 1 & 1 & 1 & 0 & 1 & 0 \\
\hline
\end{tabular}


Table 3 Distribution of the surgical procedures between the groups, $\mathrm{LI}=$ large intestinal procedure without enterotomy, $\mathrm{LIE}=$ large intestinal procedure with enterotomy, $\mathrm{SI}=$ small intestinal procedure without resection and $\mathrm{SIR}=$ small intestinal procedure with resection. | Verteilung der erkrankten Darmteile/ chirurgischen Maßnahmen innerhalb der Gruppen, LI=Dickdarmerkrankung, keine Enterotomie, LIE=Dickdarmerkrankung , Enterotomie, SI=Dünndarmerkrankung, keine Resektion, SIR=Dünndarmerkrankung, Resektion

\begin{tabular}{llllc}
\hline & \multicolumn{5}{c}{ Procedure } \\
\cline { 2 - 5 } Group & LI & LIE & SI & SIR \\
\hline Treatment & 3 & 15 & 3 & 4 \\
Control & 3 & 14 & 2 & 6 \\
\hline
\end{tabular}

\section{Discussion}

Initially the NPWT system was easy to apply to the ventral abdomen of the standing horse. The horses were still moderately sedated from general anaesthesia during the removal of the wound coverage for recovery and the application of the NPWT system, which certainly had a positive effect on their compliance. In those cases in which the wound dressing had to be renewed during the study, the application was possible without sedation in both groups. If this fact was based on the previous loosening of the wound dressing or if those horses accidentally had a high compliance remains unclear.

Final removal of the wound dressing was more problematic, because the adhesive drape and the adhesive parts of the dressings (especially the adhesive gel stripes) of both groups stuck intensively to the skin. Potentially the use of adhesive spray caused an excessive adhesion of the drape to skin and thereby pain when removing it. On the other hand a fast and strong fixation was necessary to overcome gravity when applying the drape at the ventral abdomen, which is essential for uncomplicated installation and function of the whole system.

The initial establishment of the vacuum in human medicine has been reported to be potentially uncomfortable or even painful, and the increase in pain was proportional to the increasing negative pressure when the system was applied to the forearm (Timmers et al. 2005). No adverse reactions were observed in any of the horses in this study. This difference could be explained by the fact that the horses were still sedated from anaesthesia and under the influence of analgesic medication at the initial application of the NPWT system. The reason why the three horses in which the NPWT dressing and therefore the vacuum had to be renewed during the six days study period showed no adverse reaction either remains speculative. A larger group of patients would be necessary to specify whether a high individual compliance or a generally higher tolerance of vacuum induced pain in the horse is responsible for this finding. The use of $125 \mathrm{mmHg}$ negative pressure during the therapy has been recommended in the international consensus statement for the use of vacuum therapy in human medicine (Birke-Sorensen et al. 2011). At this pressure, positive effects predominate over potential detrimental effects. The duration of therapy for NPWT varies in human medicine between four and five days (Blackham et al.
2013, Condé-Green et al. 2013) and one week (Stannard et al. 2012). The ideal duration of treatment for NPWT in horses is not known. In this study, the duration of vacuum treatment was determined at six days, because this considers the experience of human medicine and the reported occurrence of wound complications after ventral median laparotomy in horses around day seven postoperatively (Coomer et al. 2007).

The vacuum pump is equipped with a fault alarm for occurrence of leakage and thereby leakage was recognised reliably and immediately via an acoustic signal. Leakage occurred immediately after initial application in two of the first seven cases of the treatment group and, thereby, there was an inability to establish the vacuum. The dressings had to be completely changed to solve leakage. The subsequent applications in the treatment group each worked at the first attempt. There was a learning curve regarding the use of the system and, subjectively, the time needed for application decreased during the course of the study. An estimated time of 20 minutes and two people were needed for the application of the wound dressing and vacuum pump which entailed a higher workload for the staff involved. Once the vacuum was applied successfully, it was maintained reliably by the pump. During the six-day treatment period, only three wound dressings had to be renewed in the treatment group compared to seven dressings in the control group, indicating that the vacuum may help to secure the wound dressing. Since every change of a wound dressing is a potential source of contamination and potential wound infection, the constant seal of the incision during the period should be an advantage of the vacuum therapy. On the other hand, every necessary change of the wound dressing used for the vacuum system has approximately three to four times higher costs than the standard wound coverage (sterile gauze and adhesive drape).

According to recommendations in human medicine (Stannard et al. 2009), the application of the wound dressing and the vacuum system should ideally be performed directly after surgery when the surgical field is still aseptic. In this study, the vacuum system was applied after the horse's recovery. Although it did not occur, slipping of the wound dressing and consequent contamination of the incision line during recovery was theoretically possible. Applying the system with the horses standing was chosen considering the increased risk of damage to the vacuum pump and detachment of the wound dressing during recovery. Application of the wound dressing during anaesthesia without a vacuum and protection of the wound dressing by an abdominal bandage for the recovery period with subsequent installation of the vacuum in the standing horse could be an alternative solution to avoid possible slipping of the wound dressing and maintain the - at best aseptic condition at the incision line during surgery. Of course this modified approach would not have an impact on intrasurgical contamination, which is one of the main risk factors for wound healing complications (Phillips und Walmsley 1993, Honnas und Cohen 1997), but it would prevent potential contamination during recovery and especially during change of the wound dressing in a standing and moving horse. However, NPWT can effectively prevent incisions from postoperative bacterial contamination in human medicine. A tenfold higher incidence of postoperative bacterial contamination in incisions not treated with NPWT was observed in humans despite an equal degree of intraoperative contami- 
nation (Grauhan et al. 2013). This indicates that contamination in the horses with wound healing complications in this study occurred most likely during surgery, recovery or during primary postoperative dressing application, as only three dressings had to be replaced in the treatment group during the six days period of the study.

No statistical differences were found for the occurrence and severity of wound healing complications between the two groups in this study. This is in marked contrast to results from studies in human medicine treating incisions after primary closure (Blackham et al. 2013, Condé-Green et al. 2013, Reddix et al. 2009, Stannard et al. 2009). A potential reason for this difference could be the method of closure of the laparotomy. The simple continuous suture pattern that was used in this study results in a relatively tight closure of the skin due to vertical compression of the incisional margins. This could have led to impeded and therefore reduced exudate removal. Although it is known from human medicine, that primary closed wound with a similar suture pattern have been treated successfully via NPWT (Stannard et al. 2009, Grauhan et al. 2013), another suture pattern for equine laparotomy might have been more effective. For example, the method of incisional closure in one of the comparable studies from human medicine was interrupted subcutaneous stitches spaced 3 to $4 \mathrm{~cm}$ apart and skin staples at intervals of $2 \mathrm{~cm}$ (Blackham et al. 2013). It is likely that this suture pattern allowed the vacuum applied to evacuate the subcutaneous dead space of the wound and facilitated the exudate removal more superiorly. Exudate removal is an essential mechanism for the effectiveness of NPWT (Banwell 1999). Although exudate could be collected in this study in most of the horses, a different suture pattern could have led to a more effective removal of exudate and therefore lower the risk for wound healing complications in the treatment group. Additionally a higher perfusion of the area around the incision stimulated by the vacuum could lead to an increase of interstitial fluid and, consequently, to more exudate within the wound space in vacuum-treated incisions by a shift from interstitial fluid to the wound cavern (Banwell 1999). Ineffective elimination of fluid within the wound cavern due to a tight skin suture could explain the lack of beneficial effects of the vacuum therapy in this study. In the majority of the horses of the treatment group a small amount of transparent water-like fluid was collected in the collection tank and considered to be condensation water. Only three of the nine horses with clinical apparent wound healing complication showed a higher amount of exudate accumulation with a serosanguinous character during vacuum therapy. This leads to the conclusion, that on the one hand the pure amount of fluid, gained during vacuum therapy, is not a reliable predictor for severity of wound healing complications, as it seems to be a composition of exudate and condensation water. On the other hand, the fact that serosanguinous exudate, which should be expected to occur in a certain amount after every laparotomy, could only be collected from 3 of 25 horses, encourages the assumption, that exudate removal was not effective in this study, especially in the immediate postoperative period.

In the control group, no fluid accumulation occurred. During the pilot study, water accumulated under the drape supplied by the manufacturer in the control group, presumably because of its air- and waterproof properties. Consequently, a com- mercially available adhesive and breathable drape (Opsite* Incise ${ }^{\circledR}$, Smith and Nephew GmbH, Hamburg, Germany) was used in the control group of this study and no accumulation of water was seen.

In the event of bacterial wound contamination vacuum therapy was shown to have a negative effect on bacterial colonization. An increased E. coli proliferation under intermittent and continuous negative pressure compared to normal atmosphere pressure was reported in an in vitro study (Fujiwara et al. 2013). A retrospective clinical study showed that NPWT can even increase bacterial colonization within the wound although beneficial effects of this treatment modality on wound healing were noted in vast majority of cases (Weed et al. 2004). If this could be transferred to equine medicine, the use of vacuum therapy could potentially increase the proliferation of bacterial contaminants within the wound space. Provided that there was bacterial contamination to a certain extend in some cases combined with impeded exudate egress and the consequential insufficient removal of bacteria this may have contributed to the lack of beneficial effects of the vacuum therapy in this study.

It is known that there is a high risk for bacterial contamination of the wound incision during the recovery phase of the horse and therefore the use of adhesive drape during the recovery phase is recommended (Galuppo et al. 1999). The authors of another study used adhesive drape over a stent bandage for up to 5 days, which significantly reduced the likelihood of incisional infections in comparison to a group without postoperative wound coverage. Downsides of a prolonged use of adhesive drape could be the accumulation of moisture in the gauze or in the wound dressing used beneath it. This environment could promote bacterial growth (Tnibar et al. 2013). No fluid accumulation was seen in the control group of this study and the incidence of wound healing complications in this group was within recently reported limits (Mair und Smith 2005). This indicates that the use of adhesive drape during the postoperative period has no negative effect on the occurrence of wound healing complications.

Another important risk factor for wound healing complications such as suture dehiscence is excessive lateral tension in and around the incision line (Timmenga et al. 1991). In addition to the micromechanical forces leading to the increase in perfusion and cell proliferation mentioned, macromechanical forces are applied during vacuum therapy, causing a reduction in lateral tension of the wound margin. This reduction is thought to be essential to help to maintain the integrity of a closed incision (Wilkes et al. 2012). Furthermore reduction in lateral tension and therefore in stress concentrations in the tissue surrounding the incision can reduce ischaemia. Ischaemia can lead to necrosis and a decreased capacity to fight off infection (Burkhardt et al. 2008, Wilkes et al. 2012). The lateral tension at ventral midline incisions in horses is unknown but might be higher than on abdominal incisions in human medicine. It is unclear whether vacuum therapy can reduce lateral tension in ventral midline incisions in horses enough to result in a beneficial effect.

Overall, the vacuum system used in this study was easy to apply to the ventral median abdomen of horses with good toleration by the patients. The portable, battery-operated 
vacuum pump placed in a bag at the horse's neck was also well tolerated. In this study, the use of vacuum therapy for primary closure after median laparotomy had no beneficial effects. The major limitation of this study was the method of primary wound closure in a continuous simple suture pattern, which might have inhibited the exudate removal as an important mechanism of NPWT. Furthermore, our population sample was low compared to reports from human medicine. Because of the multifactorial aetiology of wound healing complications after median laparotomy in horses larger sample sizes should be considered for future studies. Regarding the increased costs for the clients and the increased workload, the value of the NWPT is questionable based on the results of this study. Due to the encouraging results of NPWT treatment in primary closed wounds in human medicine, more effort should be made to adapt the system to the horse. A different method for incisional closure of ventral midline incisions may be a first step to improve the effect of NPWT on wound healing in horses and could be evaluated in a consecutive study.

\section{Acknowledgment}

This study was supported by $\mathrm{KCl}$ Medizinprodukte $\mathrm{GmbH}$, Germany, with the supply of the vacuum pump systems. We would like to thank all our interns for their intense assistance throughout the study, especially for the wound dressing applications during night hours.

\section{Conflict of interest Statement}

The authors declare no conflicts of interest related to this study.

\section{References}

Argenta L. C., Morykwas M. J. (1997) Vacuum-assisted closure: A new method for wound control and treatment: Clinical experience. Ann. Plast. Surg. 38, 563-577

Atkins B. Z., Wooten M. K., Kistler J., Hurley K., Hughes G. C., Wolfe W. G. (2009) Does negative pressure wound therapy have a role in preventing poststernotomy wound complications? Surg. Innov. $16,140-146$

Banwell P. E. (1999) Topical negative pressure therapy in wound care. J. Wound Care 8, 79-84

Banwell P. E., Musgrave M. (2004) Topical negative pressure therapy: mechanisms and indications. Int. Wound J. 1, 95-106

Birke-Sorensen H., Malmsjo M., Rome P., Hudson D., Krug E., Berg L., Bruhin A., Caravaggi C., Chariker M., Depoorter M., Dowsett C., Dunn R., Duteille F., Ferreira F., Francos Martínez J. M., Grudzien G., Ichioka S., Ingemansson R., Jeffery S., Lee C., Vig S., Runkel N., International Expert Panel on Negative Pressure Wound Therapy [NPWT-EP], Martin R., Smith J. (2011) Evidence-based recommendations for negative pressure wound therapy: treatment variables (pressure levels, wound filler and contact layer) - steps towards an international consensus. J. Plast. Reconstr. Aesthet.ic Surg. 64, S1-16

Blackham A. U., Farrah J. P., McCoy T. P., Schmidt B. S., Shen P. (2013) Prevention of surgical site infections in high-risk patients with laparotomy incisions using negative-pressure therapy. Am. J. Surg. 205, 647-654

Burkhardt R., Preiss A., Joss A., Lang N. P. (2008) Influence of suture tension to the tearing characteristics of the soft tissues: an in vitro experiment Clinical oral implants research 19, 314-319
Condé-Green A., Chung T. L., Holton L.H. Brd, Hui-Chou H. G., Zhu Y., Wang H., Zahiri H., Singh D. P. (2013) Incisional negative-pressure wound therapy versus conventional dressings following abdominal wall reconstruction: a comparative study. Ann. Plast. Surg. 71, 394-397

Coomer R., Mair T., Edwards G., Proudman C. (2007) Do subcutaneous sutures increase risk of laparotomy wound suppuration? Equine Vet J 39, 396-399

Freeman D., Hammock P., Baker G., Goetz T., Foreman J. H., Schaeffer D. J., Richter R. A., Inove O., Magid J. H. (2000) Short and long term survival and prevalence of postoperative ileus after small intestinal surgery in the horse. Equine Vet. J. Suppl. 32, 42-51

Fujiwara T., Nishimoto S., Ishise H., Sotsuka Y., Kawai K., Fukuda K., Kakibuchi M. (2013) Influence of continuous or intermittent negative pressure on bacterial proliferation potency in vitro. J. Plast. Surg. Hand Surg. 47, 180-184

Galuppo L. D., Pascoe J. R., Jang S. S., Willits N. H. and Greenman S. L. (1999) Evaluation of iodophor skin preparation techniques and factors influencing drainage from ventral midline incisions in horses. J Am Vet Med Assoc 215, 963-969

Gemeinhardt K, Molnar J. (2005) Vacuum assisted closure for management of a traumatic neck wound in a horse. Equine Vet. Educ. 17:27-33, 2005

Gomoll A. H., Lin A., Harris M. B. (2006) Incisional vacuum-assisted closure therapy. J. Orthop. Trauma 20, 705-709

Grauhan O., Navasardyan A., Hofmann M., Müller P., Stein J., Hetzer R. (2013) Prevention of poststernotomy wound infections in obese patients by negative pressure wound therapy. The J. Thorac. Cardiovasc. Surg. 145, 1387-1392

Honnas C., Cohen N. (1997) Risk factors for wound infection following celiotomy in horses. J. Am. Vet. Med. Assoc. 210, 78-81

Jordana M., Pint E., Martens A. (2011) The use of vacuum-assisted wound closure to enhance skin graft acceptance in a horse. Vlaams Diergeneeskd. Tijdschr. 80, 343-350

Kobluk C. N., Ducharme N. G., Lumsden J. H., Pascoe P. J., Liversey M. A., Hurtig M., Horney F. D., Arighi M. (1989) Factors affecting incisional complication rates associated with colic surgery in horses: 78 cases (1983-1985). J. Am. Vet. Med. Assoc. 195, 639-642

Mair T., Smith L. (2005) Survival and complication rates in 300 horses undergoing surgical treatment of colic. Part 1: short-term survival following a single laparotomy. Equine Vet. J 37, 296-302.

Morykwas M. J., Argenta L. C., SheltonBrown E. I., McGuirt W. (1997) Vacuum-assisted closure: A new method for wound control and treatment: Animal studies and basic foundation. Ann. Plast. Surg. 38, 553-562

Phillips T., Walmsley J. (1993) Retrospective analysis of the results of 151 exploratory laparotomies in horses with gastrointestinal disease. Equine Vet. J. 25, 427-431

Proudman C. J., Smith J. E., Edwards G. B., French N. P. (2002) Long term survival of equine surgical colic cases. Part 1: patterns of mortality and morbidity. Equine Vet J 34, 432-437

Reddix R. N. Jr., Leng X. I., Woodall J., Jackson B., Dedmond B., Webb L. X. (2009) The effect of incisional negative pressure therapy on wound complications after acetabular fracture surgery. J. Surg. Orthop. Adv. 19, 91-97

Rettig M., Lischer C. (2015) Treatment of chronic septic osteoarthritis of the antebrachiocarpal joint with a synovial cutaneous fistula utilising arthroscopic lavage combined with ultrasonic assisted wound therapy and vacuum assisted closure with a novel wound lavage system. Equine Vet. Educ. 29, 27-32

Rijkenhuizen A. B. M., van den Boom R., Landman M., Cornelissen B. P. M. (2005) Can vacuum assisted wound management enhance graft acceptance? Pferdeheilkunde 21, 413

Saxena V., Hwang C. W., Huang S., Eichbaum Q., Ingber D., Orgill D. P. (2004) Vacuum-assisted closure: microdeformations of wounds and cell proliferation. Plast. Reconstr. Surg. 114, 1086-1096

Stannard J. P., Atkins B. Z., O'Malley D., Singh H., Bernstein B., Fahey M., Masden D., Attinger C. E. (2009) Use of negative pressure therapy on closed surgical incisions: A case series. Ostomy Wound Manage. 55, 58-66 
Stannard J. P., Gabriel A., Lehner B. (2012) Use of negative pressure wound therapy over clean, closed surgical incisions. Int. Wound J 9, 32-39

Stannard J. P., Robinson J. T., Anderson E. R., McGwin G. Jr., Volgas D. A., Alonso J. E. (2006) Negative pressure wound therapy to treat hematomas and surgical incisions following high-energy trauma. J. Trauma 60, 1301-1306

Timmenga E., Andreassen T., Houthoff H., Klopper P. (1991) The effect of mechanical stress on healing skin wounds: an experimental study in rabbits using tissue expansion British journal of plastic surgery 44, 514-519
Timmers M. S., Le Cessie S., Banwell P., Jukema G. N. (2005) The effects of varying degrees of pressure delivered by negative-pressure wound therapy on skin perfusion. Ann. Plast. Surg. 55, 665-671

Tnibar A., Grubbe Lin K., Thurøe Nielsen K., Christophersen M. T., Lindegaard C., Martinussen T., Ekstrøm C. T. (2013) Effect of a stent bandage on the likelihood of incisional infection following exploratory coeliotomy for colic in horses: a comparative retrospective study Equine Vet J 45, 564-569

Wilkes R. P., Kilpad D. V., Zhao Y., Kazala R., McNulty A. (2012) Closed incision management with negative pressure wound therapy (CIM) biomechanics. Surg. Innov. 19, 67-75 